Revue

de Sémantique

et Pragmatique

\section{Revue de Sémantique et Pragmatique}

41-42 | 2017

Cadrage sur la variation, le changement lexical et le changement grammatical en français actuel

\title{
La locution pronominale tout un chacun dans le système des pronoms dits indéfinis du français
}

\section{Catherine Schnedecker}

\section{(2) OpenEdition \\ Journals}

Édition électronique

URL : http://journals.openedition.org/rsp/489

DOI : $10.4000 /$ rsp.489

ISSN : 2610-4377

Éditeur

Presses universitaires d'Orléans

Édition imprimée

Date de publication : 1 décembre 2017

Pagination : 207-221

ISSN : $1285-4093$

Référence électronique

Catherine Schnedecker, «La locution pronominale tout un chacun dans le système des pronoms dits indéfinis du français », Revue de Sémantique et Pragmatique [En ligne], 41-42 | 2017, mis en ligne le 01 décembre 2018, consulté le 02 mai 2019. URL : http://journals.openedition.org/rsp/489 ; DOI $10.4000 /$ rsp.489 
ondants « simples »

ès vulgaires"

(M. Schöne, dans le Fr. mod., janv. 1947, p. 71) ; "langue familière" (Martinon, p. 167) ; "ont disparu de la langue écrite" (Dupré) ; "archaïques ou régionaux"

(Riegel, Pellat et Rioul,

iations : diatopique

(forme de régionalisme allant jusqu'au « québecquisme »), diaphasique, dia 
acun..

Merci pour les explications et corrections si je me trompe!

-dire « n'importe qui, tout le monde », est souvent remplacée par la forme s de figure qui n'arrive jamais en dehors de ces vers de Victor Hugo, tirés de «Ce siècle avait deux ans »: 
. Il est considéré comme un pronom indéfini, susceptible

ement de lui vers son objett, c'est-à-dire vers la chose dont est per

rticle indéfini, et même parfois de l'indéfini 
dèlement Frantext dans la 
t utilisé exclusivement comme un pronom nominal, ou absolu, ce que confirme, dans le tableau (1), le faible pour

acieux» pour les dames, papillons, fleurs,

it entière

uter comme 
ité humaine relativement abstraite, ce que montrent ses affinités avec les anciel se situent dans 
cela, je serais bientôt affecté à l'école primaire puis

er » aux jésuites.) (Ollivier,

directement son cul sur la selle afin que 
ns la ballonge,

es pronoms figurant dans l'annexe 1 (proposé 
éter les constituants majeurs de la structure conceptuelle :

non spécificité

et l'identifiabilité univoque du référent. Parmi les critères 
ath $(1997: 259)$

ective à ce que ce paradigme s'intéresse à l'unité.

de « saisie interne », cf. Kleiber, 2012, 59) et atteint la totalité au terme d'un parcours fictif ou virtuel, « simulé ou seulement et ne sont pas précisément prises en compte » 
vidus composant cet ensemble sont en quelque sorte « fondus dans la masse » n duquel je m'attache de préférence à ce qui fait joli et peut he de préférence à ce qui fait joli et peut oire, qui n'en redemande. 
s été mise en nourrice chez maman, que 
ante, mais

qu'elle manifeste des spécificités distributionnelles et sémantiques qui lui

'on ne veut bien le dire.

BIBLIOGRAPHIE

LIVRES :

. (2001), Indéfinis : lecture existentielles et lecture partitive, in 
lier,

r, G. (1977), La quantification universelle en français,

« singulière », 


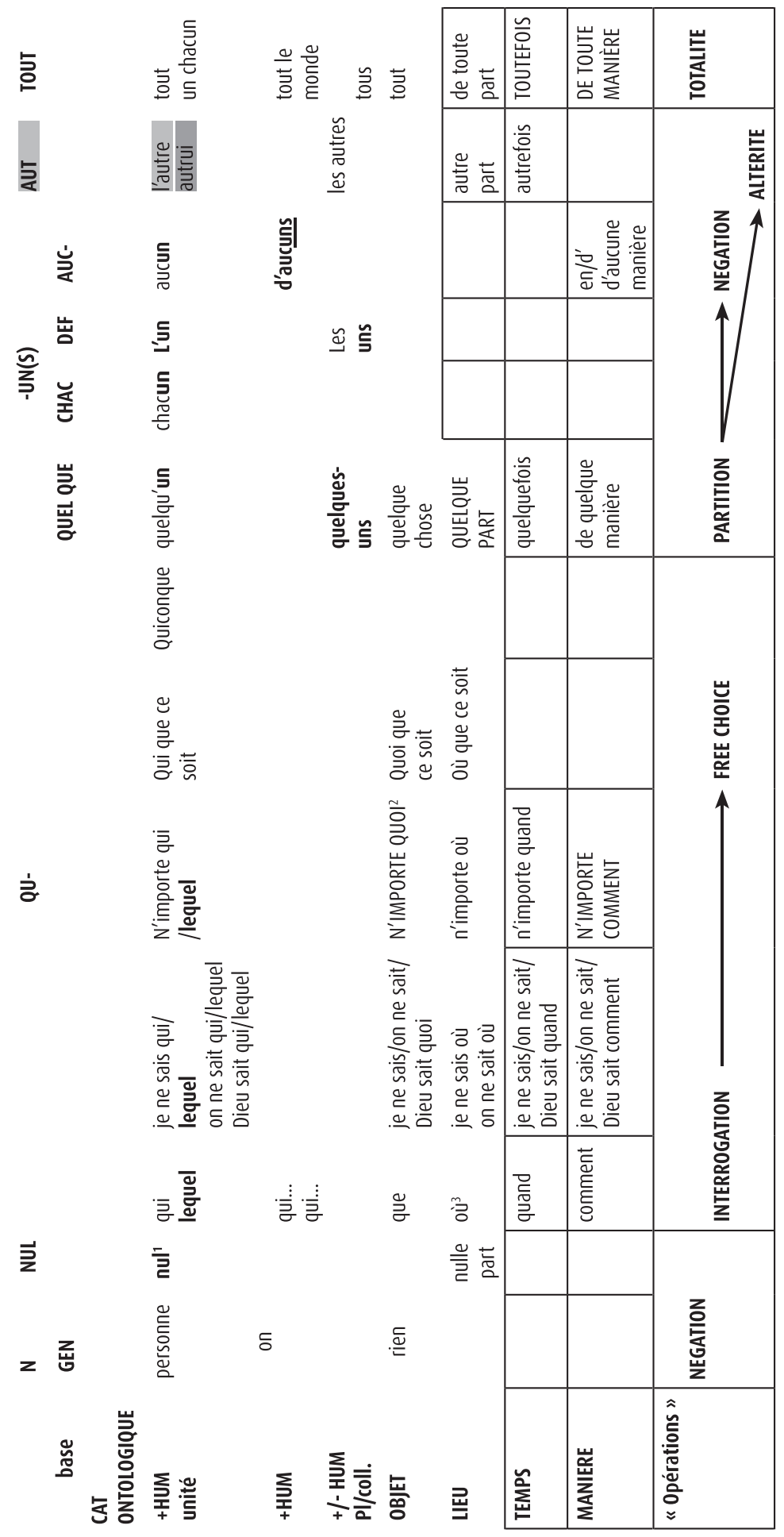

